\title{
Facing the dark side of life: The challenge of addressing users' fears in interaction design
}

\author{
Victor Kaptelinin \\ Department of Informatics, Umeå University \\ 90187 Umeå, Sweden \\ vklinin@informatik.umu.se
}

\begin{abstract}
The paper argues that fear is a powerful factor of user experience, which is likely to have a general effect on utility and usability of interactive technologies. Currently interaction design lacks methods and concepts, which would allow the field to properly understand - and deal with - users' fears. The paper presents a tentative exploration of the aims, challenges, and strategies of addressing users' fears in interaction design.
\end{abstract}

User experience, fears, interaction design, user research, design methodology.

\section{INTRODUCTION}

Interaction design has come a long way from the rational cognitivist perspective of early humancomputer interaction $(\mathrm{HCl})$. Emotions and experience are currently some of the most basic concepts in the mainstream interaction design (Norman, 2004; McCarthy and Wright, 2004).

It is widely acknowledged that a key objective of interaction design is to evoke positive emotions and support enjoyable user experience. Much less attention has been paid to users' fears. With some notable exceptions, such as designing controlledexposure virtual environments for treating phobias (e.g., Brinkman et al., 2009) and creating "scary" computer game experiences, users' fears are seldom systematically addressed in interaction design research and practice.

This paper makes the case against this somewhat lopsided (while understandable) view of emotions and experience in interaction design. It argues that fear is as important an aspect of user experience as joy and pleasure; it is likely to have a general effect on utility and usability of interactive technologies. Therefore, interaction design needs to develop methods, concepts, and practices allowing the field to better understand -- and deal with -- users' fears.

\section{TECHNOLOGY AND FEAR}

Using interactive technologies may be associated with a variety of different types of fear. First, technology itself has the ability to induce fear.
Thorne and Brosnan (2007) observe that "Fear of technology in general and of computers in particular has been shown to be prevalent in the population." Computer anxiety was found to be somewhat similar to social, performance, and test anxiety (Thorne and Brosnan, 2007). Second, in addition to being intimidated by a technology per se, users can have more or less rational concerns about potential negative effects of using the technology on users themselves (such as embarrassment, privacy violations, or security breaches), other people (e.g., distractions or insults), or material and immaterial assets (such loosing valuable information). Third and finally, using interactive technologies is just one more area, where general fears, for instance, existential fears, such as the fear of dying, can manifest themselves.

The relationship between technologies and user fears is not straightforward. On the one hand, technology seems to contribute to evoking undesirable fears and thus it is part of the problem. On the other hand, properly designed technologies can be part of the solution, for they can help people cope with fear (or invoke fear only when it is appropriate).

\section{CHALLENGES FOR INTERACTION DESIGN}

Including users' fears as yet another object of analysis and design consideration in interaction design is associated with a number of challenges, which require creative solutions. Some of the key challenges include the development of novel user research methods, as well as design principles and 
heuristics. In addition, interdisciplinary ties, especially with psychology and psychotherapy, need to be redefined and strengthened in order to provide an appropriate conceptual foundation for addressing users' fears.

User research methods. People do not easily reveal their fears, for instance, because they find it embarrassing to confess, or because a fear is displaced from consciousness and people are not aware of it. Whatever the reason, recognizing users' fears may be problematic, which presents a challenge to interaction designers, especially given that a failure to recognize users' fears can result in overlooking important design solutions.

Let us consider an example. When designing a prototype of a digitally-enhanced gym training system Blumenthal (1995) found that a key concern of potential users of the technology was about looking clumsy in front of other people. This finding resulted in a redesign of one of the components of the system, a wearable device having the shape of a wristwatch. To address potential users' concerns the designers added a new, initially unanticipated feature to the wristwatch prototype, a simple animation showing a correct way of performing an exercise. The authors specifically emphasised that traditional design approaches -- industrial design and $\mathrm{HCl}$-- were of little help when discovering the need for the new feature.

This example illustrates the limitations of common user research methods as analytical tools for supporting need and requirement elicitation based on understanding users' fears, and indicates that novel user research methods, more suitable for dealing with fears, are to be developed. The prospects for further development may include, for instance, modifying the experience sampling method (Hsieh et al., 2008) and performative techniques (Kuutti et al., 2002). The former could be used to detect transient fear responses, while the latter could facilitate revealing displaced emotions by employing "emotional probes".

Design principles and heuristics. There are several general approaches to addressing users' fears though the design of technologies. First, technologies can help minimize the level of a fear response. It can be done either by avoiding a potential threat and creating conditions, in which people would feel protected and safe, or, on the contrary, by helping people develop an ability to cope with a threat (cf. Sounders and Chester, 2008). Second, when appropriate, interaction design may be used to invoke some degree of fear, for instance when designing persuasive technologies (Fogg, 2002) intended to promote a healthier lifestyle, or when creating a special computer game experience.
These general approaches can be implemented through employing concrete interaction design strategies, such as: ensuring partial anonymity, offering scaffolding when a task is performed for the first time, supporting social sharing, prompting acceptance, providing emergency procedures, and informing about potential damages associated with certain user's choices. When implementing these and other similar strategies interaction designers will need to strike a delicate balance between addressing fears explicitly vs. implicitly, and employing standard pre-defined solution vs. ad hoc solutions.

\section{TOWARD A THEORETICAL FOUNDATION}

To adequately address users' fears interaction design will need to develop a theoretical foundation integrating conceptual influences from a range of frameworks and disciplines, including key postcognitivist frameworks in $\mathrm{HCl}$ and interaction design (e.g., Kaptelinin and Nardi, 2006). It will also need to incorporate insights from psychology and psychotherapy, especially regarding social phobias, anxiety, panic disorder, and depression.

\section{REFERENCES}

Blumenthal, B. (1995). Industrial design and activity theory: A new direction for designing computerbased artifacts. In: Human-Computer Interaction: EWHCI'95. LNCS 1015.

Brinkman, WP. et al. (2009). Field observations of therapists conducting virtual reality exposure treatment for the fear of flying. ECCE 2009.

Fogg, B. J. (2002). Persuasive technology: Using computers to change what we think and do. Morgan Kaufmann.

Hsieh, G. et al. (2008). Using visualizations to increase compliance in experience sampling. UbiComp 2008.

Kaptelinin, V. and Nardi, B. (2006). Acting with technology: Activity theory and interaction design. MIT Press.

Kuutti, K. et al. (2002). Acting to know: improving creativity in the design of mobile services by using performances. Proc. Computers and Cognition, 2004.

McCarthy, J. and Wright, P. (2004). Technology as experience. MIT Press.

Norman, D. A. (2004). Emotional Design: Why we love (or hate) everyday things. Basic Books.

Sounders, P. L. and Chester, A. (2008) Shyness and the internet: Social problem or panacea? Computers in Human Behavior. 24 (6).

Thorpe, S. J., and Brosnan, M. J. (2007). Does computer anxiety reach levels which conform to DSM IV criteria for specific phobia? Computers in Human Behavior, 23 (3). 